\title{
Effects of Household Size on Cash Transfer Utilization for Orphans and Vulnerable Children in Rural Ghana
}

\author{
Mavis Dako-Gyeke, Ph.D \\ Corresponding Author \\ Department of Social Work, University of Ghana \\ Accra, Ghana, West-Africa. \\ Email:mavisdako@yahoo.com \\ Razak Oduro \\ Department of Social Policy \\ London School of Economics and Political Science \\ London, $U K$
}

Doi:10.5901/ajis/2013.v2n1p239

Abstract

Ghana's Livelihood Empowerment Against Poverty (LEAP) program was implemented in 2008 to provide social protection to vulnerable groups, such as orphans and vulnerable children $(O V C)$. This qualitative study explored how household size influenced the extent to which the basic needs of OVC were met. A putposive sampling method was used to recruit $2 I$ households caring for OVC. In-depth interviews were conducted with $2 I$ caregivers and IO OVC, to gather data for the study. The findings indicated that household size influenced spending decisions of caregivers, although the cash transfer was conditional. Additionally, it was found that the cash received by caregivers was used to benefit all children in the households, both beneficiary and non-beneficiary. Based on the findings, we conclude that cash transfers will have the intended impact on beneficiaries if traditional family living systems and practices are taken into consideration in the design and implementation of national social protection programs.

Keywords: Caregivers, Cash transfer, Ghana, Household size, Otphans and vulnerable children

\section{Introduction}

Cash transfer is a form of social assistance, which is increasingly becoming a major part of anti-poverty policy measures in most countries. International development partners and donor agencies have recognised cash transfer as a core pro-poor development tool for reducing short-term poverty and breaking the intergenerational transmission of poverty, particularly in sub-Saharan African countries (DFID, 20I I; Holmes \& Barrientos, 2009). In different parts of the world, cash transfer systems have evolved differently because there are variations between the well established and complex social protection systems that exist in Europe and North America (Schubert \& Slater, 2006) and those in developing countries, like Ghana. The principal objective of cash transfers is to facilitate household consumption of basic needs and examples include social assistance payments, such as social pensions for the elderly, the disabled and widows as well as allowances to human immunodeficiency virus (HIV) and 
acquired immune deficiency syndrome (AIDS) orphans (Case \& Deaton, 1998; Farrington, Slater \& Holmes, 2004) and other livelihood support payments to households living below the poverty line (Slater, 20II).

As a crisis response measure, cash transfers have gained prominence in most governments' initiatives in meeting the Millennium Development Goals of 2015 (Bryant, 2009). The increased urgency, according to Adato and Basset (2009), has been as a result of continued interaction between HIV and AIDS and other drivers of poverty. Low-income countries affected by the HIV and AIDS epidemic face the challenge of providing sufficient resources to satisfy the basic needs of their members, especially poor households (Fields, 200I). In Ghana, while considerable progress has been made in reducing high poverty levels as well as the prevalence rate of HIV and AIDS, major issues still persist. For instance, I8.2 percent of Ghanaians live in extreme poverty (Adjei, Aboagye \& Yeboah, 20I2; Ghana Statistical Service, 2008) and do not have adequate resources to meet their basic food requirements (Jones, Ahadzie \& Doh, 2009). In addition, the HIV and AIDS epidemic has increased the burden of poor families in responding to their needs and that of their children, especially orphans (Marcus, 2004) and vulnerable children.

Schubert (2008) opined that poor households most often adopt micro-coping mechanisms, including withdrawing children from school, children taking up informal employment and care responsibilities among others, and these reinforce the spiral of poverty. In the process, children could become vulnerable to violence, exploitation, abuse and neglect (Badu-Nyarko \& Manful, 20I I; Jones et al., 2009). The number of children becoming vulnerable due to poverty, as well as orphans in Ghana continues to increase steadily as indicated by the Multiple Indicator Cluster Survey (MICS, 2006). The survey showed that about fifteen percent of children are not living with their biological parents and eight percent of them have one or both parents dead. In addition, the Ghana National HIV and AIDS report (2010) indicated that there were about one million and four hundred thousand orphans and vulnerable children (OVC) in 2009 and this is expected to increase to about one million and five hundred thousand by the year 20I5. These numbers present an ample concern as Lund and Agyei-Mensah (2008) contended that the increased number is likely to become one of Africa's silent ticking bombs.

The increased number of OVC suggests the need for policies and programs that could simultaneously address poverty and vulnerability among children and enable them achieve their full potential (Slater, 20II). Consequently, cash transfer has been identified as one potential way to improve the human capital development of vulnerable children (Bryant, 2009; DFID, 20II). Thus, the value of cash transfers is not only limited to its ability to tackle income poverty and support the achievement of broader social, economic and development objectives, but also to ensure the protection of society's most vulnerable groups (Mushunje \& Mafico, 2010). Evidence from Latin American countries where conditional cash transfers (CCTs) are largely implemented suggests that CCTs have been successful in countries such as Brazil, Mexico, Nicaragua, Honduras, and Columbia among others (Baird, McIntosh, \& Ozler, 20II).

Conditional cash transfer is tagged as a magic bullet in development and perceived as a panacea to escape poverty, promote inclusion and provide the much needed stimulus to enhance the human capital development of children (Adato \& Hoddinott, 2010). Conditional cash transfer schemes connect safety nets directly to human capital development, by making the receipt of cash conditional on school enrolment and /or attendance at certain health services (Handa \& Davis, 2006; Schubert \& Slater, 2006). In this regard, Ghana embraced cash transfer as an effective long-term response to extreme poverty among vulnerable groups in March 2008 and the program was named Livelihood Empowerment Against Poverty (LEAP). For the reason that strong and thorough evidence on cash transfer impacts to date come from conditional cash transfer schemes (Adatoa \& Bassett, 2009), this study focuses on LEAP's conditional cash transfer for orphans and vulnerable children. 


\section{Background of Ghana's LEAP Program}

The Livelihood Empowerment Against Poverty (LEAP) Program was implemented in Ghana to address child poverty and vulnerability. The program was first piloted in 2008 with 1,654 beneficiary households in 2I districts, began expanding in 2009 and 2010, reached 68,000 households in 2012 and is expected to increase to I65,000 households across Ghana by 2015 (Daily Graphic, 2012). LEAP is a program that aims at supplementing the incomes of dangerously poor households through the provision of cash transfers and linking them up with complementary services so that over time, they can leap out of poverty (Gbedemah, Jones \& Pereznieto, 20I0; National Social Protection Strategy, NSPS, 2007). LEAP combines both conditional and unconditional cash transfers and eligibility is based on poverty and having a household member in at least one of three demographic categories; single parent with orphan or vulnerable child, elderly poor, or person with extreme disability unable to work (PWD).

Under the LEAP, the categories of beneficiaries identified as the most vulnerable in society are: caregivers of orphans and vulnerable children (OVC); pregnant and lactating women; impoverished elderly; severely disabled persons; and households dependent on fishing and subsistence food crop farming. The LEAP program sets positive conditionalities that promote synergies with complementary social services, which include children's school enrolment and retention, registration at birth, uptake of post-natal care and immunisations for young children (Gbedemah et al., 20I0). Additionally, other conditionalities aim at eliminating certain behaviours, such as child trafficking and children engaging in worst forms of child labour.

In order for orphans or vulnerable children to qualify as LEAP beneficiaries, households through caregivers are identified and given cash every two months on condition that they (a) enrol and retain the children in school, (b) do not engage the children in exploitative labour, and (c) ensure that the children have access to health care services and nutritional food (NSPS, 2007). Since the cash transfers are time bound, households receive money for three years before they are expected to graduate from the program (Jones et al., 2009). Even though in other parts of the world, most often, women are selected as recipients of cash grant, in Ghana, the LEAP manual of operation does not include this explicitly as a requirement. Nonetheless, the NSPS recommends that female caregivers should be prioritised, as this is likely to have maximum impact on households (Gbedemah et al., 20I0).

\section{Statement of the Problem}

Although the benefits of conditional cash transfers (CCTs) with respect to meeting the socioeconomic needs of poor and needy children in Latin America and other developing countries are well documented, little is known about the effectiveness of CCTs in sub-Sahara Africa, particularly Ghana. The scarce literature available has mostly concentrated on cash transfers and poverty reduction. This research, which is part of a larger study, therefore goes beyond extant literature by exploring the effects of household size on conditional cash transfer utilisation for beneficiary orphans and vulnerable children. This is essential because households play an important role by ensuring that the needs of children are met and invariably this is influenced by the surrounding circumstances within which the household operates. As Schubert and Slater (2006) argue, there are contextual differences between countries in the quality and quantity of service provision, the capacity to implement conditionality and socio-cultural, ethnic and political contexts.

Additionally, while the conditionality of cash transfer schemes is believed to enable individual households take responsibility of beneficiary children (Lund et al., 2009), cultural beliefs and practices can influence how cash is utilised at the household level. The nature of family living in most Ghanaian communities could affect the extent to which conditional cash transfers are utilised for beneficiary 
children. In most households, family members are deeply rooted in family solidarity and engraved in the culture of sharing. Importantly, in large-sized households, sharing the cash received among targeted and other children, as well as other vulnerable persons could suggest that the targeted children will not benefit much and this could have implications for the impacts of the LEAP program. A major challenge therefore is how caregivers in poor households make decisions or are unconstrained to use the cash received on only LEAP beneficiary children.

While poor households are given conditional cash with the belief that it will have trickle-down effects on targeted children, the unconditional use of this cash may cause undesirable spending (Schubert \& Slater, 2006). This makes conditionality the most controversial part of social protection programming (Slater, 20II). Consequently, household level decision-making becomes crucial in determining how the cash is utilised and whether the targeted child or children would benefit fully from cash transfers. In this study, household is defined as a group of persons who live together as a unit with a caregiver who is responsible for their basic needs. This study therefore explored the influence of household size on conditional cash transfer utilisation for OVC in the Atwima Nwabiagya District of Ghana. The objectives of the study are:

I. To find out how household size influences cash transfer utilisation for orphans and vulnerable children with regard to provision of their school needs.

2. To determine how household size influences cash transfer utilisation for orphans and vulnerable children with regard to provision of their health needs.

3. To ascertain how household size influences cash transfer utilisation for orphans and vulnerable children with regard to provision of their food needs.

\section{Methodology}

\section{I Research Design}

This article is based on primary data collected through a qualitative research methodology. Qualitative research methods give an understanding of the situation in its uniqueness, presenting what respondents perceive about the situation and what their meanings are (Patton, 2002). A phenomenological approach of inquiry was employed for the study because it gives a description of what people experience and how they experience what they experience (Patton, 2002). Additionally, the phenomenological paradigm provides complex descriptions of how respondents experienced a given phenomenon (Mack et al., 2005). In this study, participants were given the opportunity to share their experiences regarding the LEAP's conditional cash transfer for orphans and vulnerable children.

\subsection{Study Area}

The study was conducted in the Atwima Nwabiagya District in the Ashanti Region of Ghana. It is one of the largest districts in that Region. The district was selected for the study because it was included in the LEAP pilot program in 2008. Also, a vulnerability analysis conducted through a District Survey in 2005 , indicated that some communities within the district were vulnerable, particularly children in those communities. In addition, the district was ranked third in HIV and AIDS prevalence in the Ashanti Region. For the purpose of this study, three communities within the district were selected, namely, Amadumase Adankwame, Akyena and Gyankobaa. These communities were purposively selected because they were identified by the district Social Welfare Department as areas with increasing numbers of orphans and vulnerable children. 


\subsection{Participants}

Through a purposive sampling strategy, three LEAP beneficiary communities were selected for this study. This allowed for the selection of information-rich cases whose situation illuminate questions and provides issues of importance to the purpose of the study (Patton, 2002). Twenty-one beneficiary households were selected and there were forty-three (I9 males and 24 females) LEAP beneficiary OVC in these households (Table I). Sixteen OVC were between ages five and eight, eighteen were between ages nine and twelve, and nine were between thirteen and fifteen years old. Twenty-one female caregivers, aged 20 to $70+$ years (one from each household) and ten OVC, aged IO to I5 years were interviewed.

\subsection{Data Collection Procedures}

Data was collected from respondents through in-depth interviews using open-ended questions. The open-ended interview questions provided an opportunity for the researchers and participants to discuss emerging issues in much detail. It also enabled the researchers to probe participants' responses for elaboration and to explore key issues raised by respondents, which were central to the study. The consent of the respondents was sought before the in-depth interviews were conducted. For the children, consent was sought from their caregivers and emphasis was placed on the willingness of the children themselves to participate in the study.

\subsection{Data Analysis}

Thematic analysis, a process aimed at uncovering embedded information and making explicit what respondents said, was used in analysing the data of this study (Hoepfl, 1997). Participants' responses were recorded verbatim and read thoroughly and repeatedly. The data was organised under themes based on the narrative explanations and opinions of respondents. Using the methodology of reduction, the researchers analysed the data and searched for possible meanings that made the information more meaningful and understanding (Creswell, 1998). The most illustrative quotations were used to buttress important points that emerged from the data gathered from respondents.

\section{Findings and Discussion}

\section{I Socio-Demographic Characteristics of Sampled Households}

As indicated in Table I, twenty-one households were selected from three LEAP beneficiary communities within the study area. A total number of forty-three children benefited from LEAP through their caregivers and out of this ten children were selected as participants for this study. The demographic information on the beneficiary OVC participants indicated that all of them were double orphans; they had lost both parents and were living with relatives who were their caregivers. 
Table I: Composition of LEAP beneficiary households in the study area

\begin{tabular}{|l|c|c|}
\hline $\begin{array}{l}\text { Number of sampled } \\
\text { households }\end{array}$ & $\begin{array}{c}\text { Total number of children in } \\
\text { selected households }\end{array}$ & $\begin{array}{c}\text { Number of LEAP beneficiary OVC in } \\
\text { selected households }\end{array}$ \\
\hline HH I & I & I \\
\hline HH 2 & 6 & 2 \\
\hline HH 3 & 8 & 3 \\
\hline HH 4 & 7 & 3 \\
\hline HH 5 & 3 & I \\
\hline HH 6 & 6 & 3 \\
\hline HH 7 & 5 & 3 \\
\hline HH 8 & 9 & 3 \\
\hline HH 9 & 10 & 4 \\
\hline HH I0 & 2 & 2 \\
\hline HH I1 & 4 & I \\
\hline HH I2 & 5 & 2 \\
\hline HH I3 & 6 & 2 \\
\hline HH I4 & 7 & 3 \\
\hline HH I5 & 4 & I \\
\hline HH I6 & 3 & I \\
\hline HH I7 & 8 & 2 \\
\hline HH I8 & 5 & I \\
\hline HH I9 & 7 & 2 \\
\hline HH 20 & 4 & 2 \\
\hline HH 2I & 6 & I \\
\hline Total & II8 & 43 \\
\hline
\end{tabular}

HH-Household

\subsection{Cash Transfer and Provision of Beneficiary Orphans and Vulnerable Children's Basic Needs}

Gathering information on the number of children in the households and how that influenced households' spending decisions was necessary because it could determine how cash transfers were utilised in households. The amount of money received from LEAP gets into the household purse to increase the monetary income of the household. However, decisions regarding how cash is utilised are the responsibility of caregivers, who are obliged to expend the money conditionally on beneficiary orphans and vulnerable children. In this study, beneficiary children's basic needs explored were education, health and food.

\subsection{Provision of LEAP Beneficiary OVC's School Needs}

The study found that all children of school-going age in the households included in this study, irrespective of the household size were enrolled in school. This finding suggests that the number of nonLEAP beneficiary children in the selected households did not prevent the caregivers from enrolling beneficiary OVC in school. However, it is important to emphasise that both the beneficiary and nonbeneficiary children were enrolled in school before the introduction of the LEAP cash transfer program.

Given that LEAP beneficiary households are poor and therefore retaining children in school could be a critical concern (Adatoa \& Bassett, 2009), caregivers' motivation for retaining children in school was further explored. It was found that the OVC attended public schools where students did not pay school fees because of the Education Capitation Grant introduced by the government of Ghana in the 
2005/2006 academic year. This initiative which aims at increasing access to basic education takes care of tuition fees and makes basic education free. During an in-depth interview, one caregiver remarked:

\begin{abstract}
... today, if you do not take children to school, you deny them a better future ... during my time, my father did not have money to provide us education. But now, if you go to school, you do not pay school fees... though there are other school expenses to pay, it is better to enrol children in school. (Caregiver in Household 2)
\end{abstract}

The above statement is similar to the responses of all the caregivers included in this study, which revealed that the capitation grant motivated them to enrol the OVC and other non-beneficiary children of their respective households in school. It is therefore difficult to make a linkage between beneficiary OVC's school enrolment and the cash transfer program. This notwithstanding, the importance of the cash transfer was examined beyond OVC's school enrolment. The study explored how the cash transfer was used to provide for educational materials, pay for other educational expenses and how that served as an incentive for school attendance. This is essential because beyond access to education, provision of required educational materials often becomes a challenge, especially for poor households.

It was expected that because the OVC in this study did not pay school fees, their caregivers would use the cash received to provide for other educational needs and consequently encourage school attendance and retention. It was however found that the educational needs of the OVC were not met since the conditional cash received from the LEAP program was not spent on beneficiary children alone. The caregivers used the money for all dependants in their households and this negatively affected the school attendance of OVC. Given that the LEAP beneficiary households are poor, it is likely that all the children (both beneficiaries and non-beneficiaries) in these households suffered from deprivation with regard to their educational needs except school fees, which was covered by the capitation grant. Thus, targeting only OVC in poor households may not be an effective way of reducing poverty (Farrington \& Slater, 2006) as the objectives of the conditional cash transfer program would not be achieved.

Due to the competition for educational materials among the LEAP beneficiary children and other children in the households, the caregivers used the cash unconditionally to benefit all the children. According to Schubert and Slater (2006), the unconditional use of cash transfers may cause undesirable spending. Mushunje and Mafico (2010) therefore suggest the value of cash transfers should not be limited to its ability to support the achievement of their objectives but also to ensure the protection of society's most vulnerable groups, such as all children in poor households. This is vital because children are disproportionately represented among the income-poor since majority of them suffer from severe deprivation and their vulnerability has cumulative and long-term consequences (Barrientos \& DeJong, 2004).

Even though the conditional cash transfers aim at keeping children from leaving school because of inability to pay fees or because of labour needed at home (Adatoa \& Bassett, 2009; NSPS, 2007), the LEAP beneficiary children in this study reported absenting themselves from school even when they were not sick. The reasons they gave ranged from lack of school materials which led to dismissal from class to assisting caregivers on their farms. Schubert (2008) opines that poor households most often adopt micro-coping mechanisms, including withdrawing children from school and children taking up informal employment.

The LEAP OVC in this study, especially those from households that had many non-LEAP children, revealed that they attended school two or three days in a week. This was a strategy the caregivers in those households adopted to have all the children benefit from school attendance since they did not have enough financial resources to cover the children's school expenses for the entire school 
week. The findings showed that household spending decisions were most often influenced by household size. Echoing their concerns, two LEAP beneficiary children said:

I do not go to school every day, sometimes, two days or three days in a week. . . I am in Junior High School second year, I don't have drawing board and the required mathematics book and because of that the teachers always punish me, so I find it difficult going to school every day. (A I2-year old OVC in Household I7)

I have eight siblings . . . three LEAP beneficiaries, my mother gives each of us one Ghana Cedi everyday for school. . . she says the burden is too much, so at times, we do not attend school every day... sometimes I go to school three times in a week and some of my siblings go on different days . .. when we have class test, I run to school to take the test ... also assist my mother on the farm on Fridays too. (A I5- year old OVC in Household 8)

During the interviews, the issue of OVC missing some school days because their labour was needed at home was raised. Some caregivers mentioned the option of children learning apprenticeship or engaging in trading activities if they were unable to complete their schooling due to absenteeism, among other factors. Also, when the caregivers were asked why the cash transfers were not spent on beneficiary children only because it was conditional, the caregivers indicated that it was difficult to isolate beneficiary children from non-beneficiary children since they were all members of the household and all should benefit from resources transferred to the household. This is what two caregivers had to say:

It is very difficult for me to separate my children... in the Akan tradition, your sister's children are your children, I don't want them to think I love my children more than them ... we all belong to one family, so we share what we have. (Caregiver in Household 3)

We are all having challenges in this family... I was having more difficulties more than my sister who died. We never knew such program would come to our aid. Now I have six children who are under my care including the orphaned children of my sister, how can I use the money only on my sister's children in such a situation? (Caregiver in Household 9)

In most of the households in the study area, caregivers utilised the cash received from LEAP for all children in the household irrespective of who was a beneficiary or not due to family cohesion and communal living. Although the extended family networks could negatively affect beneficiary OVC's school attendance and retention, the family is regarded the best place for caring for OVC. As Lund and Agyei-Mensah (2008) suggest, the household is an important place for effective care of OVC because of the familial and community care. In most instances, the family and the communal clan function as social support systems for individuals in need (Awusabo-Asare, 1995; Nunkuya, 1992), such as orphans and vulnerable children.

\subsection{Provision of LEAP Beneficiary OVC's Health Needs}

As part of the LEAP cash transfer conditions, caregivers are required to enrol OVC in the National Health Insurance Scheme (NHIS, NSPS, 2007). Enrolling beneficiary children in the scheme will enable them obtain NHIS cards to access free health care services at accredited health centres or hospitals. The NHIS requires annual renewal of cards by paying insurance premiums. The study explored the health decisions of caregivers with reference to OVC in their households. Specifically, the caregivers were asked whether beneficiary children were enrolled on the NHIS. If yes, how often the 
NHIS cards were renewed and if no, the alternative measures adopted by caregivers in seeking health treatment for beneficiary children were explored.

The findings revealed that, thirty-three beneficiary children were not enrolled in the NHIS, four were registered with valid NHIS cards, and six were registered but their cards had expired. Given that the conditional cash transfer payment was subject to certain types of behaviour, including clinic attendance (Farrington \& Slater, 2006; NSPS, 2007), this finding was very surprising. When asked why some beneficiary children were not enrolled in the NHIS, caregivers who had many children in their households reported it was difficult to get all the children, both the LEAP beneficiary and nonbeneficiary children registered because the financial burden was high. They stated that, the children had a lot of demands and the cash transfers were insufficient to cover all their expenses. The major challenge most caregivers faced had to do with registering only beneficiary children in their households and thereby excluding the non-beneficiary children. Two caregivers said:

... for the money, you know that the children go to school, eat everyday and have to wear clothes. I am taking care of seven children [three LEAP beneficiaries], so I was unable to register all of them. (Caregiver in Household 4)

... the money cannot cover everything ... the children are many [8 children, 3 LEAP beneficiaries] I was not able to get all of them registered... when I received the money, I bought food stuffs in order to benefit all of us. (Caregiver in Household 3 )

With regard to LEAP beneficiary OVC who had valid cards and attended hospitals, caregivers reported spending extra cash to purchase drugs which were not covered by the NHIS. This could be difficult for beneficiary households since they live below the poverty line (Slater, 20II). In order to purchase drugs that were not covered by the NHIS for OVC, some caregivers resorted to borrowing with the anticipation that when they received the cash transfer, they would use it to offset their debts. One caregiver had this to say:

... at times you go to the hospital and you are told the insurance does not cover some drugs, so I come home to bortow money to buy drugs with the anticipation that when I get the government money, I can use it to settle my debts. (Caregiver in Household 9)

Additionally, exploring the alternative healthcare methods adopted by caregivers who did not register the OVC in their households with the NHIS, it was found that some caregivers resorted to herbal medicine in treating the children when they were sick. In Ghana, many people still patronise herbal medicines due to financial constraints, lack of healthcare facilities, religious or cultural beliefs, among others (Ofori, 20II).This is common practice in rural communities, such as the study area, where caregivers have easy access to herbal plants. Commenting on the issue, one respondent mentioned that:

I do not take the children to the hospital. They do not have NHIS cards because I could not afford having all the children registered. I use herbs when they fall sick. (Caregiver in Household 8)

Furthermore, it was found that the communities included in this study had no healthcare centres and therefore the residents often had to walk long distances to the district capital in order to access healthcare services. In such situations, the main barrier to accessing health care services is not the disinclination of caregivers to send OVC to health facilities, but structural limitations of the healthcare system in Ghana. These constraints hamper access to healthcare services, particularly in rural areas where distances are immense and the transport infrastructure is deficient (Schubert \& Slater, 2006). In this 
instance, it is not the demand-side rather the supply-side bottlenecks that limit the access of poor rural households to basic health services (Schubert \& Slater, 2006). The findings suggest that the principal objective of cash transfers to enable household consumption of basic needs (Case \& Deaton, I998; Farrington et al., 2004), such as attending health clinics may not be achieved.

\subsection{Provision of LEAP Beneficiary OVC's Food Needs}

Since the LEAP cash transfer scheme is subject to certain types of behaviour, such as caregivers ensuring that orphans and vulnerable children in their care have access to nutritional food (NSPS, 2007), beneficiary households food security was explored. In this regard, questions relating to (a) the number of meals consumed per day by beneficiary OVC and (b) how household size influenced spending decisions on food were asked by the researchers. It was found that twenty-four OVC had three meals in a day and and nineteen had two meals in a day. Also, the caregivers reported spending a greater part of the cash transfer on food items due to the large number of children (both beneficiary and non-beneficiary) in their households. According to them, the cash was used up during the first week and afterwards it was difficult providing enough food for the children in their respective households. This suggests that the in-flow of the LEAP cash every two months could not sustain the households till the next payment; the length of time the cash transfer remained in the households was therefore very short.

In this study the caregivers also mentioned that the LEAP cash received was spent on the food needs of all members in each household because a household operates as a communal entity. Although, the cash transfers were to be utilised conditionally, the living arrangements, especially household size influenced spending decisions of caregivers. Thus, the cash received was used for the benefit of both OVC and other family members because each household ate from a common pot as they were considered members of one household. During the individual interviews, two caregivers remarked:

... almost all of the government money I receive through LEAP goes into the food budget. I am able to buy a lot of foodstuffs as soon as the money comes... food is very necessary so I make sure all the children eat three times a day. We all enjoy together when there is money (Caregiver in Household 15)

... the children in my house enjoy most during the first week the money is paid... I am able to buy a lot of foodstuffs... when there is no money, we do not eat much and they understand. (Caregiver in Household 9)

The above responses from the caregivers clearly indicate that they did not discriminate by ensuring that the beneficiary OVC had food while the other children in the household did not. Since the LEAP beneficiary households are dangerously poor (Holmes \& Barrientos, 2009) they do not have adequate resources to meet their basic food requirements (Jones et al., 2009). Thus, all the children in the sampled households needed food and therefore it was difficult for the caregivers to meet the conditionality of the cash transfer which was meant for the exclusive use of the LEAP beneficiaries. This was one of the reasons why some beneficiary OVC had meals twice daily. This finding could also explain why the educational and health needs of some beneficiary OVC were not met. Although, the cash transfers were to be utilised conditionally, the living arrangements, especially household size influenced spending decisions of caregivers.

With regard to the LEAP beneficiary OVC who had meals twice daily, the study found that households living arrangement influenced the cooking schedules of most caregivers. The average household normally had two meals in a day. Majority of the households were located on compounds consisting of other households and all the people on a compound were extended family members. 
During the interview, some caregivers mentioned that they did not cook in the afternoons as reflected in a caregiver's assertion:

\begin{abstract}
... we live in an extended family compound ... traditionally, cooking for lunch is not the practice, .. . so if I cook in the afternoon I am obliged to share with the all the children in the household ... I am caring for nine children, I don't have enough money to cook three times. In the evening, every mother in each household cooks so there is enough food for all the children to eat. (Caregiver in Household 8)
\end{abstract}

The findings indicated that the extended family living structure negatively affected the number of meals beneficiary OVC had in a day. While it was difficult for caregivers with many dependants (beneficiaries and non-beneficiaries) to take care of the food needs of their respective households, it was more challenging to feed all the children of the extended families in different households within the various compounds. In these households, cooking meant sharing the food to benefit all the children on a compound instead of the OVC in the beneficiary households.

As the family and the communal clan function as social support systems for individuals in need (Awusabo-Asare, I995; Nunkuya, I992), such as hungry children in low-income families, the caregivers had cultural responsibility to share the food among all the children on their compound when they cooked. However, in this circumstance, due to limited financial resources, large family sizes and cultural practices, the LEAP beneficiary OVC were deprived of lunch among other basic needs. Sharing limited resources among many children is a common practice in Ghana because the traditional household is more than the nuclear family with little consensus on its boundaries.

\title{
6. Conclusions and Implications
}

The LEAP cash transfer is a form of social protection provided by the government to meet the needs of vulnerable groups in poor households in Ghana. This study explored the influence of household size on conditional cash transfer utilisation to meet the school, health and food needs of orphans and vulnerable children in the Atwima Nwabiagya District. The findings indicated that households, which were made up of different members of the extended family operated as single units and therefore cash transfers were utilised for all children (both LEAP beneficiary and non-beneficiary) who resided in the households of caregivers. This suggests that household size influenced the spending decisions of caregivers even though the cash transfer was conditional. In practice, the cash transfer failed to meet the conditionality requirement because the money was used to meet the needs of non-LEAP beneficiary children as well.

The beneficiary children, especially those who resided in households with non-beneficiary children did not benefit much from the LEAP. Although all the OVC in this study were enrolled in school, they were deprived of other basic needs. Some caregivers were unable to (a) provide the school needs of OVC, (b) enrol OVC in the national health insurance scheme, and (c) adequately provide for the food needs of OVC. All these issues are crucial and deserve urgent policy attention because they could lead to school absenteeism and consequently have a negative impact on school retention. The LEAP program would achieve its aim of breaking the cycle of poverty in poor households if beneficiary OVC stay in school and are able to transition to higher levels of education

While the amount of cash paid to the caregivers was determined by the number of OVC in the households, it is vital to emphasise that the OVC were part of larger poor families, where majority of children in the households were non-LEAP beneficiaries. Since these households were poor, the caregivers found it difficult to utilise the cash transfer exclusively on beneficiary children as the other children in these households equally had educational, health and food needs as well. In order for the LEAP program to achieve its intended impact of reducing household poverty, the cash transfer program 
should be extended to include all children in beneficiary households since they all have unmet needs. As Slater (20II) noted, targeting specific social groupings is likely to involve major errors of exclusion. In this regard, most children in poor households in the study area were excluded from the program though they were equally vulnerable.

Even though conditionality requires behavioural change, this might be difficult to achieve in Ghana, especially in rural communities due to the extended family living system with its inherent sociocultural norms. This may influence cash transfer utilisation in households where OVC reside because the operations of these households depended largely on cohesion and sharing to benefit all family members. The conditionality notwithstanding, the caregivers made rational choices by using the cash received through the LEAP program to benefit their entire households as it was difficult to isolate the OVC from other household members. Hence, measures must be put in place to ensure that the program strengthens family cohesion rather than weakens it.

Since, the LEAP conditional cash transfer targets orphans and vulnerable children in family households, we argue that the size of the household can contribute to or diminish the potential benefits embedded in the program. Given that conditional cash transfer interventions operate through and affect complex entwined structural and traditional social relationships, the conditionality of the program must be reassessed. We therefore conclude that cash transfers will have the intended impact on beneficiaries, especially OVC if deep rooted family living systems and structural challenges, such as difficult access to health-care facilities are taken into consideration in the design and implementation of national social protection programs.

\section{References}

Adato, M., \& Basset, L. (2009). Social protection to support vulnerable children and families: The potential of cash transfers to protect education, health and nutrition. AIDS Care 2I (I), 60-75.

Adato, M., \& Hoddinott, J. (2010). Conditional cash transfers in Latin America. Baltimore, Maryland: Johns Hopkins University Press.

Adjei, P. O., Aboagye, D., \& Yeboah, T. (2012). Extreme poverty and vulnerability experiences on urban highways in Ghana: Assessing social protection policy responses. Educational Research 3(5), 436-446.

Atwima Nwabiagya District Survey. (2005). Vulnerability Analysis Report. Retrieved on April 20, 20II, from http://atwimanwabiagya.ghanadistricts.gov.gh

Awusabo-Asare, K. (1995). Living with AIDS: Perceptions, attitudes and post-diagnosis behaviour of HIV/AIDS patients in Ghana. Health Transition Review, 5, 265-278.

Baird, S., McIntosh, C., \& Ozler, B. (201 I). Cash or Condition? Evidence from a cash transfer experiment. The Quaterly Journal of Economics I26, I705-1753.

Barrientos, A., \& DeJong, J. (2004). Child poverty and cash transfers. Childhood poverty research and Policy Centre Report No. 4. London: Save the Children.

Bryant, J. H. (2009). Kenya's cash transfer program: protecting the health and human rights of orphans and vulnerable Children. Health and Human Rights, II(2), 65-76.

Badu-Nyarko, S. K., \& Saka-Manful, E. (20II). Where are the HIV/AIDS orphans? Exploring haracteristics of vulnerable children in public residential care in Ghana. Journal of Global Social Work Practice 4(I), I-I9.

Case, A., \& Deaton, A. (1998). Large scale transfers to the elderly in South Africa. Economic Journal I08(450), I330-I361.

Creswell, J. W. (1998). Qualitative inquiry and research design: Choosing among five traditions. Thousand Oaks: Sage.

Daily Graphic. (2012). 68,000 Households Benefit From LEAP. Retrieved on April 20, 2012 from http://www.ghana.gov.gh/index.php/news/features/II65I--68000-households-benefit-from-leap

Department for International Development [DFID]. (201I). Cash transfers. Evidence Paper. London: Policy Division. 
Farrington, J., Slater, R., \& Holmes, R. (2004). Social protection and pro-poor agricultural growth: What scope for synergies? Natural Resource Perspectives, 9I. Retrieved on March 22, 2012 from http://www.odi.org.uk/resources/docs/I664.pdf

Fields, G. S (200I). Distribution and development: A new look at the developing world. Cambridge, MA: MIT Press.

Gbedemah, C., Jones, N., \& Pereznieto, P. (2010). Gendered risks, poverty and vulnerability in Ghana: Is the LEAP cash transfer programme making a difference? London: Overseas Development Institute.

Ghana National AIDS/STI Control Program \& Ghana Health Service. (2010). National HIV prevalence and AIDS estimates report 2009-20I5. Accra, Ghana.

Ghana Statistical Service. (2008). Ghana living standards survey: report of the fifth round. Accra: Ghana Statistical Service.

Handa, S., \& Davis, B. (2006). Conditional cash transfers in Latin America and the Caribbean. Development Policy Review, 24(5), 5I3-536.

Holmes, R., \& Barrientos, A. (2009). Child poverty: A role for cash transfers in West and Central Africa? Briefing Paper: UNICEF and Overseas Development Institute.

Jones, N., Ahadzie, W., \& Doh, D. (2009). Social protection to tackle child poverty in $\quad$ Ghana. Briefing Paper: UNICEF and Overseas Development Institute.

Lund, R., \& Agyei-Mensah, S. (2008). Queens as Mothers: The role of the traditional safety net of care and support for HIV/AIDS orphans and vulnerable children in Ghana. GeoJournal, 7I, 93-I06.

Lund, F., Noble, M., Barnes, H., \& Wright, G. (2009). Is there a rationale for conditional cash transfers for children in South Africa? Transformation: Critical Perspectives on Southern Africa, 70(I), 70-9I.

MacAuslan, I., \& Riemenschneider, N. (20II). Richer but resented: What do cash transfers do to social relations? IDS Bulletin, 42(6), 60-66.

Marcus, R. (2004). The role of cash transfers in tackling childhood poverty. CHIP Report 2, London: Childhood Poverty Research and Policy Centre.

Multiple Indicator Cluster Survey [MICS]. (2006). Monitoring the situation of children, women, and men. Ghana, Accra: Ghana Statistical Service/UNICEF/USAID.

Mushunje, T. M., Mafico, M. (2010). Social protection for orphans and vulnerable children in Zimbabwe: The case for cash transfers. International Social Work, 53, 26I-285.

Ministry of Manpower Youth and Employment. (2007). The national social protection strategy of Ghana. Accra, Ghana.

Nukunya, G. K. (I992). Tradition and change in Ghana: an introduction to Sociology. Accra, Ghana: University Press.

Ofori, V. A. (20II). Return to natural living: the role of traditional medical practice in Ghana. Retrieved on September 25, 2012, from http://citifmonline.com/?id=I.67I653

Patton, M. Q. (2002). Qualitative research and evaluation methods. Thousand Oaks, CA: Sage Publications.

Schubert, B. (2008). Protecting the poorest with cash transfers in low income countries. In A. Barrientos \& D. Hulme (Eds.), Social Protection for the Poor and Poorest: concepts, Policies and Politics (2II-223). London: Palgrave.

Schubert, B., \& Slater, R. (2006). Social cash transfers in low-income African countries: conditional or unconditional? Development Policy Review 24(5), 57I-578.

Slater, R. (20I I). Cash transfers, social protection and poverty reduction. International Journal of Social Welfare, $20(3), 250-259$.

Woolcock, M., \& Narayan, D. (2000). Social capital: Implications for development theory, research, and policy. The International Bank for Reconstruction and Development/World Bank. 
